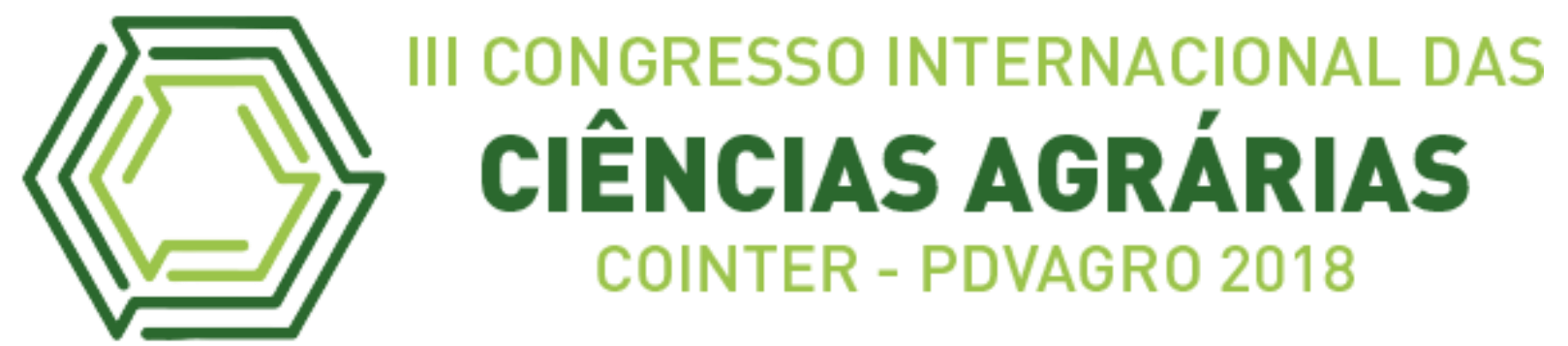

\title{
DOSES DE ADUBO POTÁSSICO INFLUENCIAM NO DESENVOLVIMENTO DA SOJA
}

\section{DOSES OF POTASSIC FERTILIZATION INFLUENCES SOYBEAN DEVELOPMENT \\ Apresentação: Pôster}

\author{
Ana Paula Rodrigues da Silva ${ }^{1}$; Wender Pereira Rodrigues ${ }^{2}$; Taynana Lima \\ Cavalcante $^{3}$;Ezequiel Lopes do Carmo ${ }^{4}$; Eduardo Carvalho Dias ${ }^{5}$ \\ DOI: https://doi.org/10.31692/2526-7701.IIICOINTERPDVAGRO.2018.00436
}

\section{Introdução}

O Brasil é o segundo maior produtor mundial de soja (Glycine max L. Merril), perdendo apenas para os Estados Unidos. Os principais fatores responsáveis por este índice é o uso de uma adubação equilibrada e o melhoramento genético. Atualmente o Brasil possui uma área plantada de 35,100 milhões de hectares e uma produção de grão de 116,996 milhões de toneladas (CONAB, 2018). Entretanto, o estado do Tocantins possui poucas regiões produtoras, com poucos dados científicos, principalmente na região sudeste. Considerando que a adubação representa uma parte considerável do custo de produção desta cultura, e que o fertilizante potássico está entre os mais exigidos pela cultura, por isso torna-se necessário investigar qual é a quantidade mais exigida pela cultura.

O Potássio é o segundo nutriente mais requerido pela soja, atrás do nitrogênio (BORKERT et al., 1994) e as maiores taxas de absorção do potássio na soja ocorre na fase vegetativa (Bataglia \& Mascarenhas, 1977). O potássio na planta contribui para realização da fotossíntese, além de apresentar funções fundamentais na ativação de mais de 60 sistemas enzimáticos em plantas. Portanto, a deficiência do potássio causa diminuição do crescimento, além de deixar a planta sujeita ao aumento de doenças, quebra de ramos, susceptível a outras condições de estresses (POTAFOS, 1990), diminuir o teor desse nutriente nas folhas, nas

\footnotetext{
${ }^{1}$ Engenharia Agronômica, IFTO campus Dianópolis, anap_rodriguess@outlook.com

2 Engenharia Agronômica, IFTO campus Dianópolis, wenderpr178@gmail.com

${ }^{3}$ Engenharia Agronômica, IFTO campus Dianópolis, taynana_Ic@hotmail.com

${ }^{4}$ Orientador, Engenharia Agronômica, IFTO campus Dianópolis, ezequiel.carmo@ifto.edu.br

${ }^{5}$ Engenharia Agronômica, IFTO campus Dianópolis, eduardo.dias@ifto.edu.br
} 
sementes, queda de produtividade (Borkert et al., 1997), redução da qualidade física, fisiológica e sanitária das sementes (Borkert et al., 1989). Por isso, o objetivo desse trabalho foi avaliar o desempenho da soja em função da aplicação de doses crescentes de potássio.

\section{Fundamentação Teórica}

Vários trabalhos foram desenvolvidos com adubação potássica em soja, mas nenhum ainda foi encontrado nas condições de Dianópolis. Considerando que a cultura extrai a maior parte do potássio presente no solo e parte deste possivelmente é perdido e/ou não é disponibilizado, torna-se necessário conhecer os efeitos da adubação potássica na cultura da soja nesta região. Em Latossolo Vermelho-Escuro fase arenosa, há necessidade de aplicar $\mathrm{K}_{2} \mathrm{O}$ superior a $80 \mathrm{~kg} \mathrm{ha}^{-1}$, visando manter a fertilidade. Porém, a dose superior a $200 \mathrm{~kg}$ de $\mathrm{K}_{2} \mathrm{O}$ ha $^{-1}$ proporcionou aumento da disponibilidade de potássio trocável na camada de 0 a 0,2 m (Rosolem \& Nakagawa, 1985). Em outro trabalho, a diminuição da disponibilidade de potássio na camada de 0,2 a 0,4 foi mais rápida quando comparada com a camada de 0 a 0,2 m porque na camada mais profunda havia maior exploração pelas raízes (Vilela \& Ritchey, 1985). Portanto, quanto existem cultivos de soja sem reposição de potássio extraído pelas plantas de soja, principalmente pelos grãos, a disponibilidade deste nutriente fica esgotada rapidamente, mesmo em condições cujo potássio trocável é considerado alto (Borkert et al.,

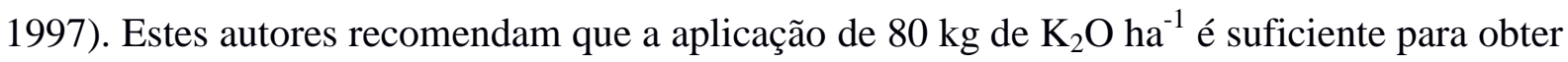
produtividades de 3,5 t de soja ha $^{-1}$ (Borkert et al., 1997) em região diferente de Dianópolis. Mas segundo Sousa \& Lobato (2004), nas condições do Cerrado, quando os níveis de potássio extraível no solo estão adequados ou altos e objetivando uma expectativa de rendimento de grãos de até 5 toneladas por hectare, as recomendações de $\mathrm{K}_{2} \mathrm{O}$ são de 100 e $70 \mathrm{~kg} \mathrm{ha}{ }^{-1}$, respectivamente.

\section{Metodologia}

O experimento foi realizado no Instituto Federal do Tocantins Campus Dianópolis, localizado à $11^{\circ} 38^{\prime} 09,66^{\prime}$ ' S e $46^{\circ} 45^{\prime} 59,38^{\prime \prime} \mathrm{O}$, a $573 \mathrm{~m}$ de altitude, na rodovia TO 040, Km 139, loteamento Rio Palmeiras, lote 01, no sudeste do estado do Tocantins. Na área onde foi implantado o experimento, realizou-se uma análise granulométrica e química de solo, antes da instalação do experimento (tabela 1). 
Tabela 1. Análise de solo

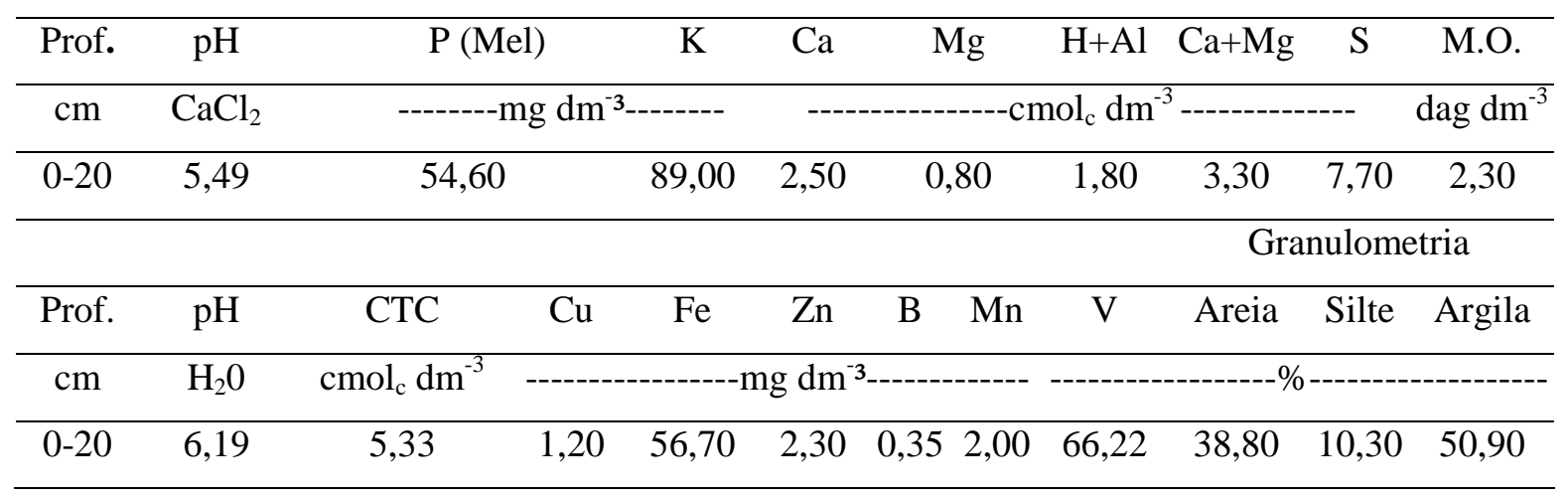

Considerando os resultados desta análise e as informações constantes no boletim Cerrado (Sousa \& Lobato, 2004), não houve necessidade de aplicação de calcário para correção da acidez, magnésio e demais nutrientes essenciais. O experimento foi implantado utilizando a cultivar de soja "BRS 9180 IPRO”, a qual apresenta características de rusticidade, elevado potencial de rendimento de grãos e estabilidade de produção em regiões que produzem esta cultura na região geopolítica do MATOPIBA, porém ainda não verificadas estas informações nas condições de Dianópolis. Este genótipo é tolerante ao glifosato e por apresentar a tecnologia Bt, há proteção contra Anticarsia gemmatalis (lagarta da soja), Chrysodeixis includens e Rachiplusia nu (lagarta falsa medideira), Heliothis virescens (lagarta das maçãs) e Crocidosema aporema (broca dos ponteiros), além da supressão a Elasmopalpus lignosellus (lagarta elasmo), Helicoverpa zea, Helicoverpa armigera e da resistência a Mancha Olho-de-rã, pústula bacteriana e cancro da haste. Apresenta ainda crescimento determinado, pubescência de cor marrom, flores de cor roxa, hilo de cor preta, altura média da planta de $100 \mathrm{~cm}$, ciclo médio de 119 a 139 dias e medianamente suscetível ao acamamento (Embrapa, 2016).

$\mathrm{O}$ delineamento foi em blocos casualizados com cinco tratamento [doses de $\mathrm{K}_{2} \mathrm{O}=0$; 17,5; 35 (recomendado por Sousa \& Lobato, 2004); 70; $140 \mathrm{~kg} \mathrm{ha}^{-1}$, na forma de cloreto de potássio] e três repetições. Cada parcela possuía $12 \mathrm{~m}^{2}$, com 8 linhas de 3 metros, cujos espaçamento foram de 0,45 $\mathrm{m}$ entre linha e 0,07 $\mathrm{m}$ entre plantas. A área útil utilizada paras as avaliações foi $6 \mathrm{~m}^{2}$.

Antes da semeadura, as sementes foram submetidas ao tratamento com inoculante líquido para soja (5 x 109 UFC de Bradyrhizobium japonicum $\mathrm{mL}^{-1}$ ). A semeadura foi realizada manualmente, com auxílio de uma régua furada, adaptada para esta finalidade. Ao longo do cultivo, quando necessário, foi realizado na área experimental o controle de fungos 
com o fungicida Tiofanato-metílico $700 \mathrm{~g} \mathrm{~kg}^{-1}$ e de insetos com inseticida sistêmico e de contato, do grupo químico metilcarbamato de oxima (215 g i.a. ha $\left.{ }^{-1}\right)$, com pulverizador costal. O controle de plantas não desejadas foi feito manualmente.

Após a colheita, foram separadas aleatoriamente 10 plantas da área útil de cada parcela. Os parâmetros avaliativos foram: altura da última vagem, altura da planta, considerando apenas a parte aérea, quantidade de vagens por planta e quantidade de entrenós.

Os dados foram submetidos ao teste de normalidade, análise de variância pelo teste $\mathrm{F}$, e quando significativo, os dados foram submetidos à regressão polinomial, utilizando o software Sisvar versão 5.6 (FERREIRA, 2003).

\section{Resultados e Discussões}

As diferentes doses de $\mathrm{K}_{2} \mathrm{O}$ influenciaram significativamente nos parâmetros avaliativos da cultura da soja (Tabela 2).

Tabela 2. Resumo da análise de variância. Fonte: Própria

\begin{tabular}{lccccc}
\hline \multicolumn{1}{c}{ FV } & SQ & QM & Fc & Pr > Fc & CV (\%) \\
\hline $\begin{array}{l}\text { Tratamento (Alt. da } \\
\text { última vagem) }\end{array}$ & 978.260476 & 244.565119 & 6.499 & 0.0165 & 6,98 \\
\hline $\begin{array}{l}\text { Tratamento (Comp. } \\
\text { Final) }\end{array}$ & 2184.021667 & 546.005417 & 15.441 & 0.0014 & 6,65 \\
\hline $\begin{array}{l}\text { Tratamento (Vagens por } \\
\text { planta) }\end{array}$ & 7851.370238 & 1962.842560 & 4.688 & 0.0372 & 16,73 \\
\hline Tratamento ( $\mathrm{N}^{\circ}$ entrenós) & 50.448333 & 12.612083 & 8.227 & 0.0088 & 8,63 \\
\hline
\end{tabular}

Para variável altura da última vagem, houve resultado significativo em relação a dose de $\mathrm{K}_{2} \mathrm{O}$, sendo que a dose de $83,18 \mathrm{~kg} \mathrm{ha}^{-1}$ de $_{2} \mathrm{O}$ proporcionou maior altura da última vagem $(100,14 \mathrm{~cm})$ (Figura 1). A variável comprimento da parte aérea da planta também apresentou resultado significativo em relação a aplicação de adubo potássico, sendo que $82 \mathrm{~kg} \mathrm{ha}^{-1}$ de $\mathrm{K}_{2} \mathrm{O}$ proporcionou maior comprimento $(102,01 \mathrm{~cm})$ (Figura 1). 
Figura 1. Parâmetros avaliados em função das doses crescentes de potássio. Fonte: Própria
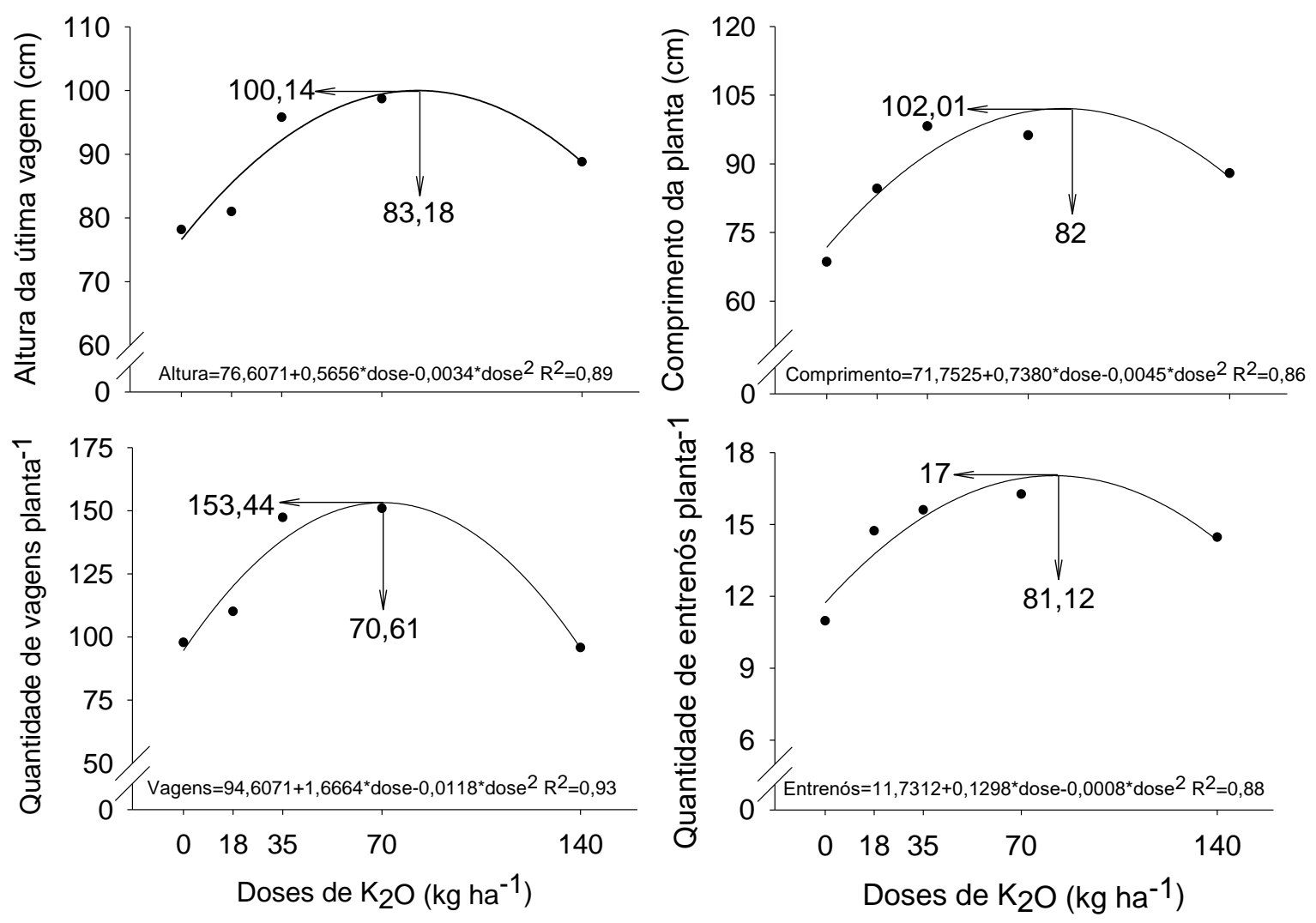

As variáveis quantidade de vagem por planta e quantidade de entrenós por planta apresentaram comportamentos diferentemente significativos, onde as doses que se observaram maiores quantidade de vagens $(153,44)$ por planta foi de $70,61 \mathrm{~kg} \mathrm{ha}^{-1}$ de $\mathrm{K}_{2} \mathrm{O}$, e 17 entrenós por planta quando aplicada $81,12 \mathrm{~kg} \mathrm{ha}^{-1} \mathrm{de}_{2} \mathrm{O}$ (figura 1).

\section{Conclusões}

As doses crescentes de potássio influenciam significativamente na altura da última vagem, no comprimento da parte aérea, nas quantidades de vagens e de entrenós da soja BRS 9180 IPRO, e as doses que proporcionam estes maiores incrementos estão entre 70,61 e 83,18 $\mathrm{kg}$ de $\mathrm{K}_{2} \mathrm{O}$ ha $^{-1}$. Entretanto, estes parâmetros precisam ser relacionados com os incrementos de grãos de soja para que possa verificar os ganhos efetivos ao produtor e a potencialidade de cultivar este genótipo na região de Dianópolis-TO. 


\section{Referências}

BATAGLIA, O. C.; MASCARENHAS, H.A.A. Absorção de nutrientes pela soja. Campinas, Instituto Agronômico de Campinas, 36p., 1977. (Boletim Técnico, 41)

BORKERT, C. M et. al. Seja o doutor da sua soja. In: Informações Agronômicas, Piracicaba, n.66, 16p. Junho de 1994.

BORKERT, C..M et. al. Resposta da soja à adubação e disponibilidade de potássio em Latossolo Roxo cutrófico. Pesquisa Agropecuária Brasileira, Brasília, v.32, n.10, p.I009IO22, out. 1997.

BORKERT, C. M. el. al. Potassium fertilization reduces seed infection by Phomopsis sp. and improves seed quality. In: WORLD SOYBEAN RESEARCH CONFERENCE, Buenos Aires. p.2265-2275, 1989.

CONAB. Acompanhamento da safra brasileira de grãos. 2017/2018. v. 5. p. 96-101, 2018.

EMBRAPA. Cultivar de Soja para o MATOPIBA. 1 ed. 2016.

FERREIRA, D. F. SISVAR: sistema para análise de variância. Lavras: UFLA, 2003. (Software estatístico).

POTAFOS. Potássio: necessidade e uso na agricultura moderna. Associação Brasileira para Pesquisa da Potassa e do Fosfato. Tradução Bernardo van Raij. Piracicaba: POTAFOS, 45p. 1990.

ROSOLEM, C. A.; NAKAGAWA, J. Potassium uptake by soybean as affected by exchangeable potassium in soil. Communications in Soil Science Plant Analysis, New York, v. 16, n. 7, p. 707-726, 1985.

SOUSA, D. M. G.; LOBATO, E. Cerrado: Correção do solo e adubação. Planaltina, Embrapa Cerrados, 2004. 416p.

VILELA, L; RITCHEY, K.D. Potassium in intensivo cropping systems on highlyweathered soils. In: MUNSON, LtD., cd. Potassium ia agriculture. Madison, American Society of Agronomy. p. 1 55-76, 1985. 